\title{
Significados da finitude no mundo vivido de pessoas com HIV/ AIDS: um estudo fenomenológico
}

\section{Meanings of finitude in the lived world of people with HIV/ AI DS: a phenomenological study}

\author{
Virginia Moreira* \\ Universidade de Fortaleza - UNIFOR, Fortaleza, Ceará, Brasil
}

Lucas Bloc**

Universidade de Fortaleza - UNIFOR, Fortaleza, Ceará, Brasil

Marcio Rocha***

Universidade Federal do Ceará - UFC, Sobral, Ceará, Brasil

\begin{abstract}
RESUMO
Este estudo trabalha um dos temas emergentes relativos à pesquisa longitudinal fenomenológica, o qual diz respeito ao estigma na doença mental em portadores do HIV/AIDS: a morte. Pretende-se compreender os significados da morte e da finitude e sua repercussão no mundo vivido de pessoas com HIV/AIDS. Foi utilizado o método fenomenológico mundano e reanalisadas 50 entrevistas com pacientes portadores de HIV/AIDS na referida pesquisa. Os resultados revelam que o momento da descoberta da doença, a iminência de sintomas e suas consequências, são os momentos descritos onde significados relativos à morte estão mais presentes. Significados da finitude repercutem no mundo vivido dos entrevistados e a possibilidade iminente da morte configura-se como fator de sofrimento e agravamento da doença.
\end{abstract}

Palavras-chave: Morte, HIV/AIDS, Método fenomenológico.

\begin{abstract}
This study further develops one of the themes emerging from a phenomenological longitudinal research on the stigma of the mental disease and HIV: death. It aims to investigate the meanings of death and finitude and its repercussions in the lived world of people living with HIV. We use the phenomenological mundane method and reanalyzed interviews with 50 patients with HIV in this research. The results show that the moment of discovery of the disease and the imminence of its symptoms and consequences are the moments described in which meanings of death are most present. Meanings of finitude impact the lived world of the respondents and the possibility of imminent death has become a factor of suffering and of aggravation of the disease.
\end{abstract}

Keywords: Death, HIV / AIDS, Phenomenological method. 


\section{I ntrodução}

A morte pode ser considerada um aspecto fundamental no mundo vivido de todas as pessoas. No caso de quem vive com HIV/AIDS, este mundo vivido é bastante peculiar. Mesmo com o avanço científico no combate ao vírus, a manifestação dos sintomas e o agravamento da doença, associados à perspectiva da morte, repercutem fortemente na vida dessas pessoas.

O HIV/AIDS vem produzindo vítimas em todo o mundo. Estimativas da Organização das Nações Unidas (ONU) aponta para um número de 25 milhões de vítimas (WHO/UNAIDS, 2008). No entanto, desde sua descoberta, é possível evidenciar evoluções tanto no aspecto biológico quanto no social. O tratamento tornou-se mais consistente com o desenvolvimento de alguns medicamentos que, embora não eliminem a doença, permitem um quadro estável da patologia, possibilitando ao paciente uma vida saudável. No aspecto social, novas concepções sob o conceito de grupo de risco foram geradas, mostrando que todas as pessoas, dependendo de seu comportamento, podem contrair o vírus. É possível dizer que houve um avanço com o aumento da sobrevida e a melhora da qualidade de vida (FERREIRA, 2003).

Para compreender 0 HIV/AIDS, considera-se fundamental empreender um olhar fenomenológico, com múltiplos contornos. No texto intitulado La doute de Cézanne, Merleau-Ponty (1966) realiza uma analogia entre o seu pensamento filosófico e a obra do pintor francês Paul Cézanne (1839-1906).

Para o filósofo, a pintura de Cézanne, que se mostra deformada e com múltiplos contornos, é muito mais real do que uma fotografia, que traz uma realidade exata e estática. Merleau-Ponty pensa uma realidade sempre em movimento e deformada, já que não existe uma demarcação definida entre real e imaginário. Nesse sentido, o pensamento de Merleau-Ponty define-se por uma ruptura das dicotomias, a partir de um reconhecimento das ambiguidades próprias do ser humano, e pela idéia de um sujeito constituído por múltiplos contornos (MOREI RA, 2002).

Assim, a partir do pensamento de Merleau-Ponty, pode-se pensar também o HIV/AIDS como constituído por múltiplos contornos: biológicos, sociais, morais e culturais, os quais atravessam esta experiência de se viver com o estigma da doença, trazendo ainda mais sofrimento ao paciente.

Mesmo considerando o contorno biológico de maior gravidade, assim como o forte estigma presente na sociedade (GOOD, 2002), a morte como possibilidade iminente é um dos fatores que mais gera sofrimento ao paciente. Discutir a forma como as pessoas que vivem com HIV/AIDS significam morte e finitude, torna-se fundamental para 
se pensar todo o sofrimento vivenciado diante de uma doença sem cura e capaz de trazer vários malefícios aos seus portadores.

Este estudo buscou aprofundar a temática da morte, que foi um dos temas emergentes ${ }^{1}$ em uma pesquisa longitudinal fenomenológica sobre a experiência vivida do estigma na doença mental e no HIVIAIDS (MOREIRA; MELO; BLOC; TELLES; ARAÚJ O; EVANGELISTA, 2010).

Embora a pesquisa investigasse a experiência vivida sobre o estigma em torno da doença mental e do HIV/AIDS, a questão da morte emergiu nas entrevistas com pessoas que vivem com HIV/AIDS. Assim sendo, objetivou-se investigar os significados da morte no mundo vivido de pessoas com HIV/AIDS, suas repercussões na vida e a possibilidade da iminência da morte ser um possível fator de sofrimento adicional. Nesse sentido, foi fundamental levarmos em consideração a disseminação, o desenvolvimento e o estágio atual da doença para a compreensão de sua lógica e das possíveis repercussões nos sujeitos colaboradores deste estudo. Foi utilizado um referencial teórico fenomenológico-existencial, recorrendo, em especial, ao pensamento de Martin Heidegger para compreender a iminência da morte e a finitude, sob a ótica das pessoas que vivem com HIV/AIDS.

\section{$1.1 \mathrm{HIV} / \mathrm{AI}$ DS}

Embora possa parecer redundante, é importante fazer uma breve distinção pontual daquilo chamado mundialmente de HIV e daquilo chamado de AIDS. O HIV (Vírus da Imunodeficiência Adquirida) pertence à classe dos retrovírus e é o causador da AIDS. Ele pode ficar silencioso e incubado por muitos anos, agindo no sistema imunológico. Já a AIDS é uma doença clínica decorrente do quadro causado pelo HIV, caracterizando-se por uma supressão profunda da imunidade, resultando em infecções oportunistas, neoplasias secundárias e doenças neurológicas (BRASIL, 2006).

A AIDS atravessa pelo menos três fases. Na primeira fase, não é perceptível, é assintomática e somente reconhecida em exames de laboratório. Na segunda, surgem algumas manifestações que sugerem um sistema imunológico deteriorado. Na terceira fase, as doenças oportunistas e outras doenças consequentes da deterioração do sistema imunológico aparecem (FERREIRA, 2003).

Alguns dados epidemiológicos atuais indicam que, até 2007, 25 milhões de pessoas morreram de AIDS no mundo (WHO/UNAIDS, 2008). Segundo o relatório da UNAIDS/WHO² de dezembro de 2007, em torno de 33.2 milhões de pessoas vivem com HIV e, apenas em 2007, existem 2.7 milhões de novos infectados. Ainda neste mesmo ano, morreram 2.1 milhões de pessoas em consequência da AIDS. 
No Brasil, até dezembro de 2006, cerca de 190 mil pessoas morreram de AIDS (BRASIL, 2008). A incidência brasileira, de 1980 a junho de 2007, chega a 474.273 casos de AIDS, havendo uma estimativa de que, em 2012, 638 mil pessoas estarão vivendo com HIV/AIDS no país (BRASIL, 2008). Estes dados nos permitem ter uma dimensão da amplitude quantitativa da doença no país. Além disso, estas estatísticas tão alarmantes podem justificar a elaboração de medidas com vários focos diferentes, indo desde a prevenção até a busca de uma melhor qualidade de vida.

\subsection{Morte HIV/ AI DS}

A finitude é característica ontológica do ser humano, bem como as múltiplas maneiras de lidar com ela. Por muito tempo se entendeu que o soropositivo vive uma situação de morte anunciada (FERRAZ, 1996), com a qual teria que conviver a todo o momento, tornando-a muito mais próxima e presente. A contaminação não representa mais uma sentença de morte absoluta; é possível viver de forma saudável e assintomática por muitos anos.

Além da saúde física, é fundamental destacar-se a saúde psicológica dessas pessoas. Em sua experiência clínica, Ferreira (2003) mostrouse surpreso ao dar-se conta de que a dor psicológica era maior do que a dor física, fundamentando ainda mais a noção de que a reação ao conhecimento da doença é subjetiva, indo de acordo com a sanidade mental de cada um - a pessoa reage não como quer, mas como pode.

O diagnóstico torna presente os medos, angústias, conflitos e culpas, além de ameaçar planos futuros. A angústia pela possibilidade da morte é um fator dificultador e gerador de sofrimento, pois pode impedir mudanças necessárias para se continuar vivendo nesse novo contexto. A renúncia à própria vida, embora distante do desejo de morrer, é uma das reações encontradas - o indivíduo pode deixar de trabalhar e de se divertir, caindo no isolamento (FERREIRA, 2003).

Quando se nega a existência da morte, se perde uma oportunidade de buscar os significados da vida. No entanto, quando a dor e a doença são colocadas como possibilidade de ampliar a capacidade das pessoas de aprender e evoluir, a dor e o sofrimento tendem a expandir essa capacidade (SILVA, 1996). A morte em um futuro mais próximo pode gerar muita dor, mas, ao mesmo tempo, pode trazer o sujeito mais para o presente (BELOQUI, 1992). No caso de pessoas com HIV/AIDS podemos exemplificar com duas experiências: primeiramente, há indivíduos que conseguem alguns anos de vida saudável e percebem que podem fazer muitas coisas e viver bem. A segunda refere-se a pessoas que, após o diagnóstico, ficam deprimidas e desanimadas. Para estas, não resta fazer nada além de esperar a morte chegar (FERREIRA, 2003). 
Diante da morte, se relativizarmos todas as condições sociais, há um nivelamento do homem ao mesmo destino e situação. Porém, seu significado vai além da dimensão natural e biológica, comportando, como qualquer fato humano, uma dimensão social e particularidades dentro da história de vida do indivíduo e das modalidades do seu fim (MARANHÃO, 1985). Culturalmente, na sociedade ocidental, não existe o hábito de conviver nem de pensar na morte como algo natural; evita-se bastante falar no processo de morrer e nas causas da morte (ARIĖS, 2003; FERRAZ, 1996; KÓVACS, 1992; MARANHÃO, 1985).

Moraglia (2004) realizou um estudo teórico sobre a morte na visão de alguns, chamados por ele, de proeminentes psicólogos representantes da psicologia moderna, indo de Gustav Fechner e William James a Carl Rogers e Skinner. O autor concluiu que, na visão da maioria desses autores, uma confrontação com a mortalidade pode se constituir como uma das precondições necessárias para o crescimento psicológico, não sendo mórbida ou inimiga da vida.

Heidegger (1989), afirma que uma psicologia do morrer "acaba fornecendo mais soluções sobre a 'vida' 'dos que morrem' do que propriamente sobre o morrer" (p. 29), podendo funcionar até mesmo como um crescimento. Deixar de viver não implica na perda dessa condição ontológica que justifica a vida. A "interpretação existencial da morte precede toda biologia ou ontologia da vida" (p. 29). Uma pessoa com HIV/AIDS está remetida continuamente, pela sua condição ontológica e por seu adoecimento, à contingência inevitável da morte. Assim, saber que vai morrer deixa a pessoa em condições de pensar os modos como vai querer viver, considerando a sua condição atual.

\subsection{Morte: uma perspectiva ontológica}

Neste artigo, utiliza-se a compreensão existencialista de morte como um processo determinante da própria condição da vida (FORGHIERI, 1984). O homem não pode e nem deve "iludir a consciência da morte ou recusar a angústia e o desespero que a consciência da morte acarreta" (OLSON, 1970, p. 227). Ao neutralizar a consciência da morte, o ser humano estaria privando à vida o seu supremo valor: a intensidade. A perspectiva fenomenológico-existencial de Martin Heidegger é aquela que foi considerada mais adequada para se pensar a morte, na situação vivida por pessoas com HIV/AIDS.

O se-saber e o se-sentir mortal permitem o discurso sobre a relação do homem com sua própria mortalidade - são os fundamentos da experiência que o ser humano tem de si mesmo. Tal discurso é fenomenológico, pois se refere ao "apresentar-se a si mesmo do caráter finito de sua existência" (DASTUR, 2002, p. 57). 
Mas como seria possível descrever a maneira como o ser humano se relaciona com a própria morte se ela é, por excelência, um nãofenômeno? Heidegger nos dá abertura para se pensar a morte em sua iminência, não como um fenômeno particular, mas como aquilo que produz em todos os outros fenômenos seu conteúdo ímpar de finitude, o que torna possível um discurso fenomenológico sobre a mortalidade (DASTUR, 2002).

Heidegger (1989) defende a busca do sentido existencial da morte na própria vida, mostrando que ela pode constituir todo o ser. A morte é um modo de ser que a vida assume, bastando estar vivo para morrer e, como tal, deve-se assumi-la em seu caráter ontológico, próprio do ser. A morte é a certeza indefectível, irremissível e insuperável, sendo, ao mesmo tempo, a mais extrema. Este caráter da morte é gerador de angústia, mas não em seu sentido fraco e casual, e sim como uma abertura para a consciência de que, como ser lançado no mundo, existimos para o fim.

A exterioridade da morte é colocada como traço produtor de terror e instiga uma atitude de inautenticidade. Heidegger defende uma atitude resoluta: assumir a finitude - algo que aliviaria o temor inspirado da iminência da morte e abriria caminho para uma totalidade que não é possível em vida, mas que poderia se tornar um paradigma em vida sobre nós mesmos como uma totalidade (DASTUR, 2002; OLSON, 1970).

A morte é concebida como a última situação-limite do homem e coloca o homem como um "ser-para-a-morte", pois como ela só acontece uma vez e extingue todas as possibilidades do ser sujeitos, experimenta-se o sentimento do Ser-para-a-morte diariamente, ou seja, experimenta-se constantemente a relação com a morte (DASTUR, 2002; RÉE, 2000).

O medo de defrontar-se com a morte faz com que, muitas vezes, o ser refugie-se em uma existência inautêntica, em uma fuga da angústia da morte. É justamente na angústia que a mortalidade se revela "autenticamente" (DASTUR, 2002, PENHA, 1982). Existir autenticamente para a morte significa liberdade em relação a ela, ou seja, "liberar a morte de todos os estratagemas no meio dos quais tentamos domá-la, seduzi-la e neutralizá-la, para deixá-la reinar inteiramente sobre nossa existência e atribuir-lhe, assim, a possibilidade de tornar-se senhora da existência do Dasein" (DASTUR, 2002, p. 86).

O homem inautêntico tende a aliviar o medo da morte, atribuindo-lhe um caráter impessoal, abstrato e universal, reduzindo a morte a uma dimensão social e biológica, deixando de reconhecê-la como um fenômeno ao qual todos estão submetidos individualmente (HEIDEGGER, 1989, OLSON, 1970).

A morte é, incontestavelmente, um "fato da experiência" humana, porém deixada de lado e atribuída ao impessoal "morrem" ou morre- 
se. A morte que é sempre minha, de forma essencial e insubstituível, converte-se num acontecimento público, que vem ao encontro no impessoal. O discurso assim caracterizado fala da morte como um "caso" que permanentemente ocorre, mas encobre o caráter de possibilidade e os momentos que lhe pertencem de irremissibilidade e insuperabilidade (HEIDEGGER, 1989, p. 35).

Rigorosamente, a certeza da morte só é possível empiricamente e tal distanciamento se torna uma tentativa de fugir da angústia trazida por ela e da sua compreensão mais fiel - como a possibilidade mais certa do ser-no-mundo. A função do impessoal é barrar a coragem de assumir a angústia com a morte e encobrir o mais característico da morte - sua possibilidade a cada momento (HEIDEGGER, 1989).

Para Heidegger (1989), o ser-para-a-morte é, essencialmente, angústia e o homem só alcança a plenitude de seu ser justamente nessa angústia, penetrando o mais particular e íntimo de seu ser. 0 homem deve reconhecer que "a morte é o acontecimento último de sua vida, evento ímpar, rigorosamente pessoal [...]. Assumindo a morte, o Dasein alcança sua autenticidade, pois já não a teme" (PENHA, 1982, p. 47). O reconhecimento da finitude é fundamental na cruzada por uma vida autêntica, marcando toda a busca por uma completude, da qual falamos anteriormente, da existência humana.

Segundo Heidegger, a forma de compreensão da significação da totalidade da existência é trazer consigo a morte como uma certeza indefinida, mas iminente; algo possível a todo instante (RÉE, 2000). A relação mantida pelo homem com o morrer é constitutiva do seu ser e anterior às suas outras determinações. A morte constitui, para Heidegger, essencialmente a relação do Dasein com o próprio existir, chamado por ele de existência, mas que não pode se tornar um "acontecimento do mundo", já que se configura justamente como fim deste, se revelando em sua constante iminência (DASTUR, 2002).

Na obra Ser e Tempo, Heidegger compreende a temporalidade como circular e não fragmentada em passado, presente e futuro - não se vive o tempo, se é o tempo. Morrer é um elemento estruturante de nossa existência e toda concepção de humano que possuímos é perpassada pela ideia da mortalidade. A partir dela, compreende-se afetos, sentimentos, manifestações sociais etc., pois só assim se estabelecem as relações com o outro (ROTHSCHILD; CALAZANS, 1992). O tempo perpassa a existência humana, bem como a iminência da morte. Resta sabermos como cada sujeito vive e sente tais questões, principalmente porque são aspectos que o singularizam amplamente. 


\section{Método}

Neste estudo foi utilizado o método fenomenológico mundano (MOREIRA, 2004, 2009), que busca compreender, com base na fenomenologia de Merleau-Ponty, os significados emergentes da experiência vivida de pessoas que vivem com HIV/AIDS em seus múltiplos contornos, levando-se em consideração aspectos biológicos, culturais e situacionais (MOREIRA, 2002), os quais caracterizam a mundaneidade dos sujeitos.

A fenomenologia de Merleau-Ponty é utilizada, buscando-se situar a essência na existência, a fim de compreender o homem e o mundo a partir de sua facticidade. Trata-se de uma tentativa de retornar à experiência vivida da forma mais íntegra possível, buscando-se deixar de lado, momentaneamente, juízos e crenças que possam distorcer 0 real sentido da experiência. A impossibilidade desta redução fenomenológica completa é seu maior ensinamento, o que não diminui seu valor dentro da pesquisa fenomenológica (MERLEAUPONTY, 1945). Como caráter fundamental da pesquisa fenomenológica mundana, busca-se sempre o significado da experiência e, para se compreender tal experiência, utiliza-se uma compreensão mundana, implicando um olhar crítico e abrangente de um sujeito enraizado no mundo e marcado por múltiplos contornos que o subjetivam (MOREIRA, 2004, 2009).

Durante a pesquisa "A experiência vivida do estigma: um estudo sobre a doença mental e HIV/AIDS no Nordeste do Brasil" (MOREIRA ET AL., 2010) foram realizadas, longitudinalmente, um total de 50 entrevistas com 30 pacientes com HIV/AIDS divididas em seis séries de entrevistas. Na primeira série foram entrevistados 30 sujeitoscolaboradores; na segunda, 21; na terceira, 13; na quarta, sete; na quinta ${ }^{3}$, dois e na sexta, sete entrevistados. É possível observar uma crescente diminuição do número de sujeitos-colaboradores e tal diminuição consiste também em um dos resultados da pesquisa, como uma possível descontinuidade dos pacientes e dificuldade no tratamento em um hospital público, onde foi realizada a pesquisa. Como critério de inclusão os pacientes deviam ser portadores do vírus HIV/AIDS, adultos, de ambos os sexos, estar em tratamento em um hospital público de Fortaleza e estar de acordo em participar da pesquisa assinando um termo de consentimento.

Como instrumento foi utilizado a entrevista fenomenológica, cuja pergunta disparadora (MOREIRA, 2004, 2009) foi: "Como é para você a experiência de ter esta doença"? As entrevistas foram gravadas e transcritas. Para fins deste estudo, foram reanalisadas as 50 entrevistas realizadas com pacientes com HIV/AIDS, focalizando, agora, as questões relativas à morte e ao morrer.

As etapas utilizadas na reanálise dessas entrevistas foram, a partir de Moreira (2004, 2009), as seguintes: 1) Divisão da entrevista 
transcrita em movimentos, segundo o tom da mesma; 2) Análise descritiva dos significados emergentes do movimento; 3) "Sair do parênteses". A primeira etapa consistiu em uma divisão em temáticas daquilo que emergiu em relação ao fenômeno, no caso, a morte. A segunda foi uma descrição dos significados que emergiram sobre a morte. Já a terceira e decisiva etapa é caracterizada como o momento na análise fenomenológica em que a redução fenomenológica não é mais utilizada. Pensamentos, interesses e teorizações que no decorrer da análise da pesquisa tentamos deixar de lado, neste momento, passaram a ser novamente consideradas. Ou seja, saímos do parênteses e retornamos à fundamentação teórica que havíamos tentado deixar de lado. Relembramos novamente, a partir de Merleau-Ponty (1945), que a principal característica da redução fenomenológica é que ela nunca se completa, mas deve ser sempre uma tentativa, "um artifício para revelar o mundo" (MOREIRA, 2009).

\section{Resultados e discussão}

Como resultados relativos à reanálise das entrevistas transcritas, focalizando especificamente o tema morte, foram estabelecidas as seguintes categorias fenomenológicas:

\subsection{A descoberta da discussão}

O momento da descoberta da doença mostrou-se um momento muito delicado para os entrevistados, trazendo várias incertezas e forçando alguns a lidarem com sua finitude. Um dos entrevistados relatou seu nervosismo ao descobrir ter a doença e ter pensado:

Ana: [...] "A morte tá na minha frente", então, eu encarei assim. Aí eu fiquei muito depressiva [...]

E: Qual era o sentimento que veio, assim, na hora?

Ana: Primeiro Dra., eu achava assim, passou a morte ali na minha frente. O que vinha na minha cabeça era isso, né, de eu morrer.

Embora a mortalidade esteja presente sempre em nossa vida, com a descoberta da doença, o paciente passa a encará-la como uma real possibilidade - um sofrimento para alguns. Outro entrevistado colocou que dali em diante sua vida tinha acabado:

J oão: Pra mim, a vida já tinha acabado.

A descoberta, para outro entrevistado, Ihe tirou a esperança e a fé, tendo a vida perdido o sentido:

Pedro: Já perdi as esperança, já perdi a fé [...]É dizer assim: eu vivo por viver, porque nesse dia mais, se fosse por mim, se dependesse de mim, eu já tinha sumido já. Entendeu? 
As reações emocionais diante da descoberta da doença são diversas e forçam o sujeito a lidar com a condição de viver com uma doença para a qual, até então, não existe cura. Não há dúvida da grande carga emocional despejada nestes sujeitos e, se não houver uma preparação no momento da descoberta e nos primeiros meses, o impacto emocional pode ser ainda maior, podendo, inclusive, causar danos ao próprio tratamento.

\subsection{Medo da morte}

O medo da morte, apesar de ser um sentimento comum nas pessoas, se acentua em alguns sujeitos ao se depararem com a doença. Há uma espécie de angústia diante da certeza da morte, um medo de morrer crescente ao se deparar com a doença e suas consequências. Em alguns casos, passa a ser a preocupação central da vida do sujeito. Uma entrevistada relatou seu forte medo de morrer e o quanto isso atrapalha sua vida, facilitando até mesmo o aparecimento de outras doenças:

E: Você se sente envergonhada por causa da doença?

Ana: Não.

E: Não?

Ana: Só tenho medo que envolva morte. Minha preocupação toda tá aí. O que passa pela minha cabeça é só isso, que ela vai matar logo a gente.

E: O que você acha dessa doença, como é conviver com ela?

Ana: Dra de início é muito difícil, terrível, porque a gente sabe, assim, que é uma doença crônica, mas eu acho que com o tempo a gente vai melhorando [...].

E: Fale um pouquinho [...].

Ana: É o que eu falei Dra., que eu penso assim, que eu vou morrer logo. Encaro logo a morte na frente, não é? É isso que me atrapalha mais, porque agente fica achando que não tem cura, e agente tem medo, aí outras doenças vêm.

Este mesmo sujeito-colaborador, em outra entrevista, afirmou ter depressão e a atribuiu claramente ao medo de morrer, associando até mesmo as possíveis baixas imunológicas a tal estado emocional:

E: E qual é o motivo da depressão?

Ana: Medo de morrer. Isso Dra, de morrer. Não porque todos nós sabemos que vamos morrer. Mas assim, queria viver mais [...] eu fico pensando assim, que eu vou morrer, eu acho que eu não duro mais nem dois anos [...]. A Dra mesma fica assim: "Ana, seu CD4 não passa de 200. 130 ele está". Aí eu digo: "Eu não sei Dra. Acho que é esse meu sistema nervoso". Ela acha que é também, que derruba muito. 
Já outro entrevistado relatou medo de morrer, mas sim de fome e não de AIDS, mostrando o quanto as questões sociais, e não só as biológicas, estão envolvidas na condição de vida destas pessoas.

Pedro: Eu sinceramente tenho medo de morrer de fome e não morrer de AIDS.

A morte atravessa a condição humana e traz com ela o medo de morrer e a incerteza diante do que pode acontecer após a morte. Diante disso, é necessário que o homem assuma a morte como condição ontológica; o que está em jogo é seu ser-no-mundo diante da possibilidade mais própria, irremissível e insuperável do homem (HEIDEGGER, 1989). A relação do ser humano com o morrer é anterior a todas as outras determinações, ela é o que constitui a relação do ser-no-mundo com seu próprio existir (DASTUR, 2002). A angústia trazida pelo medo da morte pode se configurar como uma dificuldade, própria da condição humana, de assumir sua finitude e como uma possibilidade de se ter uma vida autêntica, buscando uma totalidade, uma plenitude em vida como um paradigma a ser seguido, mesmo não sendo alcançado em vida (DASTUR, 2002; OLSON, 1970).

O temor da morte pode assumir um caráter patológico, como na entrevistada que o coloca como o motivo de sua depressão. Embora não exista um diagnóstico, não há como não considerar os sintomas depressivos, que modificam significativamente sua forma de viver, e que estão diretamente relacionados com a doença, além de poderem se constituir como um fator agravante. Ainda que não haja uma homogeneidade de estudos sobre depressão e a evolução do HIV, em todos há uma associação entre a depressão e um pior prognóstico da infecção (STUMPF; ROCHA; PROJ ETTI, 2006).

O medo de morrer de fome, relatado por Pedro, serve de alerta para atentar-se para as questões sociais que também atravessam estes sujeitos, e para não olhar para eles com a ideia de um Homo Aidéticos, como enfatiza Silva (1996), mas como um homem mundano, sujeito e objeto do mundo constituído por contornos biológicos, culturais, sociais, históricos e políticos (MOREIRA, 2002, 2007).

Viver com HIV/AIDS pode significar ter que conviver com problemas como redução de renda, empregabilidade precária, discriminação e preconceito, endividamento pessoal e etc., evidenciando-se uma grande vulnerabilidade social e a necessidade do desenvolvimento de políticas públicas que possam ir além do caráter puramente de saúde (COSTA-COUTO, 2007). Infelizmente, a questão da vulnerabilidade social e o consequente empobrecimento por conta da epidemia de AIDS têm sido pouco estudados. Estratos mais pobres da população têm se tornado mais vulneráveis por questões predominantemente biológicas e sociais - imunidade mais baixa, menor capacidade de atendimento pela grande demanda e infraestrutura precária são 
alguns exemplos (BASTOS; SZWARCWALD, 2000). No caso de Pedro, citado anteriormente, não é possível discutir a gênese de seu posicionamento diante de questões tão densas como o HIV/AIDS e a fome, mas fica claro o entrelaçamento de sua doença com sua condição social e a influência disso nos significados atribuídos à morte.

\subsection{Os sintomas}

O vírus do HIV se mostra muitas vezes invisível, alguns entrevistados até afirmaram esquecer que estão com vírus, pois não apresentam nenhum sintoma. O aparecimento dos sintomas e a necessidade da medicação são algumas das questões trazidas pelos sujeitos e que os leva a questionar realmente o caráter finito de sua existência. Eles têm que conviver com a incerteza da manifestação dos sintomas que podem estar por vir, como afirmou um dos sujeitos:

Raquel: Porque eu acho que você é soro hoje, eu to só com o vírus, eu não sei daqui a três, quatro, cinco, seis anos. Se ela vai se desenvolver ou não, sempre vou continuar com o vírus né? Você tem que ter sempre em mente isso. Você pode até passar dez, vinte anos só com o vírus, mas um dia você vem a desenvolver.

Outra entrevistada relatou o seu medo de entrar em uma crise e como isso a afeta, ocasionando, inclusive, uma depressão:

Maria: Então eu estou nessa fase de depressão, fico dentro de casa, só sofrendo, sabe, sem ânimo, sem força, sem, não consigo trabalhar, não consigo sabe, não consigo produzir, porque não me deixa, eu não tenho força para seguir adiante.

E: Você acha que isto que está acontecendo com você tem a ver com a doença?

Maria: Eu acho que, ó, pelos medos que eu to tendo, sabe? De entrar numa crise, de, sabe assim, de apresentar algum quadro que precise, que seja necessário eu ter que me internar, sabe, tudo isso. Sabe, e já vai me dando um medo, uma coisa.

A incerteza quanto ao tempo de vida pela chegada dos sintomas, pode significar viver mais o presente, como afirmou um entrevistado:

Rafael: Eu tinha um plano pro futuro, agora eu não tenho mais [...] tenho o presente, quero viver somente o presente [...] às vezes quero deixar alguma coisa pra amanhã, até algum curso quando aparece, aí eu, "não, vou deixar pra depois, acho que ano que vem eu faço", aí eu fico pensando "não, vou fazer agora, porque nunca se sabe".

Outra entrevistada associou o resultado dos exames à contagem do seu tempo de vida e falou do temor de ter que iniciar a medicação. Para ela, é necessário deixar a doença em segundo plano para poder viver, algo complicado quando os sintomas aparecem: 
Maria: [...] parece assim, a contagem da sua vida, quanto tempo você tem [...] pra começar a tomar o coquetel [...] acho que todo soropositivo assintomático, ele teme isso, né, de tomar o coquetel. [...] não é que vou esquecer, mas que não seja (a doença) o centro das suas atenções [...] você precisa deixar isso em segundo plano porque se não você não faz mais nada na sua vida [...] Agora quando você já passa a ter sintoma, né, você perde peso [...] você ta caminhando já pro começo do grande fim. Pior do que o resultado, porque você começa a ver as perdas.

A questão do suicídio, embora tenha emergido na fala de apenas um entrevistado, demonstra a forte presença do estigma e a possível repercussão negativa no sujeito, levando-o, neste caso, a uma tentativa real de suicídio:

Otávio: [...] aí eu fiquei tão preocupado assim, aí eu comprei o chumbinho e aí tomei. Porque eu achava que ela (a esposa) estava fazendo chantagem comigo, tava me humilhando demais, aí pra mim conviver com a família dessa maneira aí. Eu não sei até quando vocês vão conviver com esse tipo de doença que não tem cura porque eu acho que o melhor meio seria esse mesmo.

Silva (1996) destaca as incertezas vividas por estes sujeitos como um dos temas mais comuns. Vive-se com a incerteza de quando aparecerão os sintomas, como agirão, como a medicação deverá ser usada, quais os efeitos colaterais e etc. Podemos observar claramente nas falas o sofrimento trazido por estas questões e como afetam as pessoas.

É importante ressaltarmos a atitude de um dos entrevistados que, ao deparar-se com a finitude, com as incertezas da vida acentuadas pela doença, acaba trazendo-a mais para o presente e de uma forma mais autêntica. Ele não tenta burlar a angústia trazida pela consciência da finitude, mas sim viver o presente de forma mais intensa.

\subsection{HI V/ AI DS = morte}

A associação entre HIV e morte é feita, muitas vezes, por outras pessoas e, não pelos pacientes, ou, até mesmo, pela mídia. Um entrevistado relatou a mudança do comportamento de algumas pessoas próximas ao saberem de sua doença:

Rafael: Porque a gente vê que as pessoas têm a gente como se a gente tivesse vivendo o último dia.

Outro entrevistado afirmou que para muitas pessoas AIDS é sinônimo de morte e, para ele, a mídia contribui para isso:

Sérgio: [...] pra muitas pessoas esse sinônimo de AIDS já é a morte, né, num sabe dos tratamentos e também porque como a TV divulga, né, fala: "Ah esse pessoal morreu de AIDS", mas não fala do tratamento que é tão bem, né? 
Uma visão equivocada e negativa da AIDS foi relatada por outro sujeito-colaborador, atribuindo à mídia um papel de disseminadora de tal concepção errônea, pois para ela, a AIDS não significa a impossibilidade de ser feliz:

Fernanda: [...] não é assim destrutivo, tão negativo [...] eu acho que as pessoas têm um impressão destrutiva do HIV. É difícil? É. É terrível? Com toda certeza é, né? Não é assim também a coisa mais simples do mundo, mas assim eu acho que a própria mídia passa pras pessoas uma visão muito pesada, muito negativa. A pessoa tem que mostrar o rosto e dizer que mesmo tendo HIV ela pode ser feliz.

Quando o tema HIV/AIDS surgiu na mídia ele, necessariamente, era associado aos homossexuais e prostitutas e a uma rápida morte. Eram valores sustentados pelo saber médico e por uma cultura preconceituosa e moralista. Com o desenvolvimento da medicina e, de certa forma, uma maior aceitação social dos chamados grupos de risco, tais concepções tiveram uma tendência a diminuir. No entanto, a associação com a morte ainda é muito presente, sempre atrelada à ideia de se viver com uma doença que não tem cura e com a associação com ícones brasileiros que morreram de AIDS como, por exemplo, Cazuza, quando, na verdade, existem vários exemplos de pessoas que vivem bem por décadas. A forte associação das outras pessoas entre morte e HIV é, para Goffman (1989), também uma manifestação de estigma, um dos tipos de discriminação ao reduzir sem pensar e de forma generalizada a chance de vida de quem sofre. Visualizar a atuação da mídia é fundamental tanto para a compreensão da doença, por parte dos pacientes, quanto da sociedade, pois o reconhecimento da possibilidade de uma vida digna sendo soropositivo é importante como uma via de combate ao estigma, como uma forma de enfrentamento, a fim de evitar um aprisionamento em um ideário de morte que só tende a antecipá-la.

\section{Considerações finais}

Embora o tema da morte não tenha sido o objeto inicial da pesquisa sobre a experiência vivida do estigma (MOREIRA; MELO; BLOC; TELLES; ARAÚJ O; EVANGELISTA, 2010), esta temática foi observada nas falas dos sujeitos-colaboradores, fato que levou à realização desta segunda etapa da pesquisa, no sentido de aprofundar qualitativamente o tema morte na experiência vivida de pacientes com HIV/AIDS.

Abordar esta temática significa ir além do pensar a morte e o morrer, refletindo, principalmente, sobre a vida e seu caráter finito. Quando se reflete sobre a morte tem-se necessariamente que se pensar em vida, pois vida e morte constituem um único fenômeno que se apresenta como fundo sobre o qual a existência se desenrola em um 
duplo movimento ontológico (viver e morrer) que marca o sujeito em seu vir-a-ser (CRITELLI, 1988). E quando isto é abordado sob a lógica de uma doença crônica, imunológica, globalizada e repleta de significados sociais como a HIV/AIDS ainda é mais significativo. Nas falas de alguns entrevistados percebe-se que a forma com que eles lidam com a morte é a mesma com que lidam com a doença. Encarar a morte e a finitude de forma saudável e não cristalizadora, pode viabilizar formas de vida mais autênticas e potencializadoras. No entanto, quando restringem o sujeito a uma vida de medo, despotencializada por uma possibilidade inerente e sempre presente de morrer, acabam muitas vezes restringindo as formas de vida dessas pessoas e, pode-se dizer, minando suas resistências diante do HIV/AIDS.

As três primeiras entrevistas, realizadas com cada sujeito colaborador em períodos mais próximos ao recebimento do diagnóstico, foram os principais momentos utilizados pelos entrevistados falando sobre como se sentiam diante da possibilidade da morte e sobre a finitude. A descoberta da doença e o deparar-se com a iminência de sintomas e suas consequências parecem ser os momentos mais difíceis. Ao descobrirem que estão infectadas, as pessoas se deparam com a presença no corpo de um vírus, até o momento, impossível de curar e com todos os atributos sociais ainda presentes. Embora alguns relatem esta experiência de forma calma e serena, a grande maioria demonstra o choque e toda a angústia trazida pela descoberta. 0 medo de morrer torna-se um sentimento acentuado e gerador de muito sofrimento. Nas falas dos sujeitos fica clara a necessidade de um cuidado especial por parte dos profissionais da saúde com este momento inicial, bem como com o impacto do diagnóstico nos primeiros meses logo após a descoberta da doença.

Os sintomas funcionam como um "termômetro", sempre existindo incerteza quanto ao curso da doença e a administração dos medicamentos. Percebemos o grande sofrimento trazido por esta incerteza e pelas possíveis consequências, entre elas, a possibilidade da morte e uma "despotencialização" (MOREIRA, 2002) da vida pelo fato destas pessoas não acreditarem que seja interessante um investimento em algo fadado ao fim. Não é por acaso que tantos pacientes com HIV/AIDS sofrem de depressão (STUMPF; ROCHA; PROJ ETTI, 2006). No momento da descoberta da doença e com as incertezas acirradas quando do surgimento de sintomas, estes pacientes deparam-se mais intensamente com a finitude de que nos fala Heidegger.

Os significados da morte repercutem no mundo vivido dos sujeitos e a possibilidade iminente da morte se configura muitas vezes como fator de sofrimento. Não podemos dizer que o significado da finitude muda a partir da doença, mas fica clara a necessidade dos sujeitos "re-configurarem" ou "re-significarem" sua existência. A grande 
questão parece ser como conviver com o vírus, seja na família, no trabalho, nas relações afetivas, etc.. Ao negar a angústia diante da finitude, a pessoa se priva da intensidade da vida e evita a verdade sobre si mesmo, passando a viver uma existência inautêntica (HEIDEGGER, 1989). A existência autêntica, reconhecendo a própria finitude da vida e podendo, a partir disso, lidar com ela, fazer suas escolhas e conduzir a vida, poderia permitir a estas pessoas uma vida melhor.

\section{Referências}

ARIÈS, P. História da morte no ocidente: da idade média aos nossos dias. Rio de Janeiro: Ediouro, 2003.

BASTOS, F. I.; SZWARCWALD, C. L. AIDS e pauperização: principais conceitos e evidências empíricas. Cadernos de Saúde Pública [online], Rio de Janeiro, v. 16, sup. 1, p. 65-79, 2000. Disponível em: <www.scielo.br>. Acesso em: 20 jul. 2009.

BELOQUI, J. A polaridade vida-morte e a AIDS. In: V. Paiva (Org.). Em tempos de AI DS. São Paulo: Summus, 1992, p. 27-31.

BRASIL. Ministério da Saúde. Secretaria-Executiva. Secretaria de Vigilância em Saúde. Glossário temático: DST e AIDS. Brasília: Editora do Ministério da Saúde, 2006.

BRASIL. Ministério da Saúde. Secretaria-Executiva. Secretaria de Vigilância em Saúde. UNGASS - Resposta Brasileira 2005 2007: Relatório de Progresso do País. Brasília: Editora do Ministério da Saúde, 2008. Disponível em: <http://bvsms.saude.gov.brs>. Acesso em: 09 fev. 2010.

COSTA-COUTO, M. H. A vulnerabilidade da vida com HIV/ AI DS. 2007. 211f. Tese (Doutorado em Medicina) - Instituto de Medicina Social, Universidade do Estado do Rio de Janeiro, Rio de Janeiro, 2007.

CRITELLI, D. M. O des-enraizamento da existência. In: M. F. S. F. B. Dichtchekenian (Org.). Vida e morte: ensaios fenomenológicos. São Paulo: Editora C. I., 1988, p. 15-28.

DASTUR, F. A morte: ensaio sobre a finitude. Trad. Maria Tereza Pontes. Rio de Janeiro: DIFEL, 2002.

FERRAZ, A. Refletindo sobre o ser portador do HIV ou doente com AIDS e o relacionamento interpessoal. In: SILVA, R. G. (Org.). Ação e vida: respostas à epidemia de HIV/AIDS em Belo Horizonte. Belo Horizonte: Secretaria Municipal de Saúde, 1996, p. 179-208.

FERREIRA, C. V. L. AI DS e exclusão social: um estudo clínico com pacientes com o HIV. São Paulo: Lemos Editorial, 2003.

FORGHIERI, Y. C. Temas existencialistas. Conceitos Fundamentais. In: FORGHIERI, Y. C. (Org.). Fenomenologia e Psicologia. São Paulo: Cortez Autores Associados, 1984. 
GOFFMAN, E. Estigma: notas sobre a manipulação da identidade deteriorada. Rio de Janeiro: Guanabara, 1989.

GOOD, B. Stigma. Research project. Boston: Department of Social Medicine, Harvard Medical School, 2002.

HEIDEGGER, M. O ser e o tempo (Parte II). Trad. de Márcia de Sá Cavalcante. Petrópolis, RJ : Vozes, 1989.

KOVÁCS, M. J. Representações de morte. In: KÓVACS, M. J. (Coord.). Morte e desenvolvimento humano. São Paulo: Casa do Psicólogo, 1992, p. 1-13.

MARANHÃO, J. L. de S. (1985). O que é morte. Col. Primeiros Passos. São Paulo: Brasiliense, 1985.

MERLEAU-PONTY, M. Phénoménologie de la Perception. Paris, Gallimard, 1945.

. La doute de Cézanne. In: MERLEAU-PONTY, M. Sens et nonsens. Paris: Nagel, 1966.

MORAGLIA, G. On Facing Death: Views of Some Proeminent Psychologists. Journal of Humanistic Psychology, v. 44, p. 337354, 2004. Disponível em: <http://online.sagepub.com>. Acesso em: 14 dez. 2009.

MOREIRA, V. Psicopatologia Crítica (Parte II). In: SLOAN, T.; MOREIRA, V. Personalidade, I deologia e Psicopatologia Crítica. São Paulo: Escuta, 2002, p. 109-248.

. O método fenomenológico de Merleau-Ponty como ferramenta crítica na pesquisa em psicopatologia. Psicologia: Reflexão e Crítica, v. 17, n. 3, 2004, p. 1-15.

. De Carl Rogers a Merleau-Ponty: a pessoa mundana em psicoterapia. São Paulo: Annablume, 2007.

Clínica Humanista-Fenomenomenológica: estudos em psicoterapia e psicopatologia crítica. São Paulo: Annablume, 2009.

MOREIRA, V.; MELO, A. K.; BLOC, L.; TELLES, T.; ARAÚJO, T.; EVANGELISTA, K. Fenomenologia do estigma em HIV/AIDS e na doença mental. Latin American Journal of Fundamental Psychopathology On Line, v. 7, n. 1, p. 45-74, maio de 2010. Disponível em: <www. fundamentalpsychopatology.org>. Acesso em: 04 dez. 2010.

OLSON, R. G. Introdução ao existencialismo. Trad. D. Forjaz Neto. São Paulo: Brasiliense, 1970.

PENHA, J. O que é existencialismo. Col. Primeiros Passos. São Paulo: Brasiliense, 1982.

RÉE, J. Heidegger: história e vida em Ser e o Tempo. São Paulo: Ed. UNESP, 2000.

ROTHSCHILD, D.; CALAZANS, R. A. Morte - Abordagem Fenomenológico-Existencial. In: KÓVACS, M. J. (Coord.). Morte e desenvolvimento humano. São Paulo: Casa do Psicólogo, 1992, p. 145-152. 
SILVA, R. G. O apoio psicológico aos portadores do HIV/AIDS. In: SILVA, R. G. (Org.). Ação e vida: respostas à epidemia de HIV/AIDS em Belo Horizonte. Belo Horizonte: Secretaria Municipal de Saúde, 1996, p. 179-208.

STUMPF, B. P.; ROCHA, F. L.; PROJETTI, A. B. Infecções virais e depressão. J ornal brasileiro de psiquiatria, Rio de Janeiro, v. 55, n. 2, 2006. Disponível em: <www.scielo.br>. Acesso em: 28 jul. 2009.

UNAIDS. Joint United Programme on HIV/AIDS. AIDS epidemic update. United Nations \& AIDS, 2009. Disponível em: <www.unAIDS.org>. Acesso em: 22 dez. 2009.

\section{Endereço para correspondência Virginia Moreira}

Av. Washington Soares, 1321, Bloco N, sala 13, CEP 60811-905.

Endereço eletrônico: virginiamoreira@unifor.br

\section{Lucas Bloc}

Av. Washington Soares, 1321, Bloco N, sala 13, CEP 60811-905.

Endereço eletrônico: lucasbloc@yahoo.com.br

\section{Marcio Rocha}

Av. Lucia Saboia,215, Sobral - CE, CEP 62.010-830

Endereço eletrônico: arthoni@yahoo.com.br

Recebido em: 01/07/2010

Reformulado em: 03/01/2011

Aceito para publicação em: 08/02/2011

Acompanhamento do processo editorial: Eleonôra Torres Prestrelo

\section{Notas}

*Professora Titular do Mestrado em Psicologia da Universidade de Fortaleza, Ceará, coordenadora do APHETO - Laboratório de Psicopatologia e Psicoterapia Humanista Fenomenológica Crítica. Doutora em Psicologia Clínica pela PUC-SP (1990) com PósDoutorado em Antropologia Médica por Harvard University. Endereço para correspondência: APHETO - Laboratório de Psicopatologia e Psicoterapia Humanista-Fenomenológica Crítica, Mestrado em Psicologia, Universidade de Fortaleza (UNIFOR), Fortaleza, Ceará, Brasil.

** Professor da Universidade de Fortaleza, Ceará, mestre em Psicologia pela Universidade de Fortaleza (UNIFOR) e membro do APHETO - Laboratório de Psicopatologia e Psicoterapia Humanista Fenomenológica Crítica.

*** Professor da Universidade Federal do Ceará, Sobral-CE. Doutorando em Psicologia na Universidade de Fortaleza e integrante APHETO - Laboratório de Psicopatologia e Psicoterapia Humanista Fenomenológica Crítica.

${ }^{1}$ Os temas emergentes são todas as temáticas que surgem dentro de uma pesquisa fenomenológica, mesmo aquelas que não consistem diretamente foco da pesquisa. No caso deste artigo, é abordada a morte.

${ }^{2}$ Este é um relatório do desenvolvimento global da epidemia de AIDS, desenvolvido pela UNAIDS (United Nations Programme on HIV/AIDS) e pela WHO (World Health Organisation) ou, como chamada no Brasil, OMS (Organização Mundial de Saúde).

${ }^{3}$ Nesta série de entrevistas, algumas fitas apresentaram problemas de ordem técnica. 